\title{
Human brucellosis in the Emirate of Abu Dhabi, United Arab Emirates, 2010-2015
}

(1) CrossMark

Nawal Al Shehhi ${ }^{1}$, Faisal Aziz², Farida Al Hosani ${ }^{2}$, Bashir Aden ${ }^{2}$ and lain Blair ${ }^{{ }^{*}}$ (I)

\begin{abstract}
Background: Worldwide, human brucellosis remains an important and widespread infection. In the past, there were limited data on the occurrence of human brucellosis in the United Arab Emirates and the reported incidence appeared to be low compared with similar areas. In 2009, a new web-based infectious disease surveillance system was introduced in the Emirate of Abu Dhabi. This paper reports data from this new system on human brucellosis for the 6 years 2010 to 2015.

Methods: A dataset was extracted for each case of human brucellosis reported to the notification system for the 6 year period January 2010 to December 2015. Annual brucellosis rates by age-group, gender, nationality and, geographical region were calculated and compared.

Results: A total of 480 cases of brucellosis were reported. The overall crude notification rate was $3 \cdot 3$ per 100,000 population but higher rates were seen in certain population subgroups notably expatriate males of working age in the Eastern Region (approximately 10 per 100,000) and UAE nationals of all ages and both genders in Abu Dhabi (between 4 - 24 per 100,000).

Conclusions: These findings reflect environmental and behavioral factors linked to occupation and leisure time activities associated with the large number of small non-commercial livestock farms in Abu Dhabi. Controlling human brucellosis in these circumstances will be challenging.
\end{abstract}

Keywords: Human brucellosis, Brucella, Incidence, United Arab Emirates, Abu Dhabi, Emirati

\section{Background}

Globally, human brucellosis remains an important and widespread infection [1]. As a zoonosis, the occurrence of human brucellosis is largely dependent on its animal reservoir [2]. The main animal species that are affected are food-producing animals such as cattle, sheep, goats and, pigs but in some regions camels, dogs and, horses are significant sources of infection. Transmission from animal to human is usually due to the consumption of unpasteurized milk and dairy products or by direct contact, often in an occupational setting, with infected animals or their close environment, particularly at the time of parturition. There is wide between and within country variation in the occurrence of human brucellosis due to demographic and socioeconomic factors and the implementation of surveillance systems and animal-based control

\footnotetext{
*Correspondence: lain_blair@uaeu.ac.ae

${ }^{2}$ Institute of Public Health, College of Medicine and Health Sciences, United

Arab Emirates University, PO Box 17666, Al Ain, United Arab Emirates

Full list of author information is available at the end of the article
}

programs. Some countries have reduced and even eliminated brucellosis (France, Israel, Latin America) while others are seeing an emergence or re-emergence (Central Asia) [3].

In the past, there has been limited data on the occurrence of human brucellosis in the United Arab Emirates (UAE) and the reported incidence appeared to be low compared with other countries in the Region. A widely quoted 2006 study reported a rate of $4 \cdot 1$ per 100,000 population per year [3]. Although animal (sheep, goat, camels) surveillance data is sparse it is likely that in the UAE there is a significant animal reservoir of Brucella infection $[4,5]$. A recent systematic review of human and animal brucellosis in the Middle East supported the widespread presence of Brucella in the region. Fifteen countries had at least one occurrence of Brucella melitensis and nine reported Brucella abortus. Four studies gave reliable estimates of brucellosis in ruminants of $2-10 \%$ in individual animals and up to $50 \%$ for flocks while only 


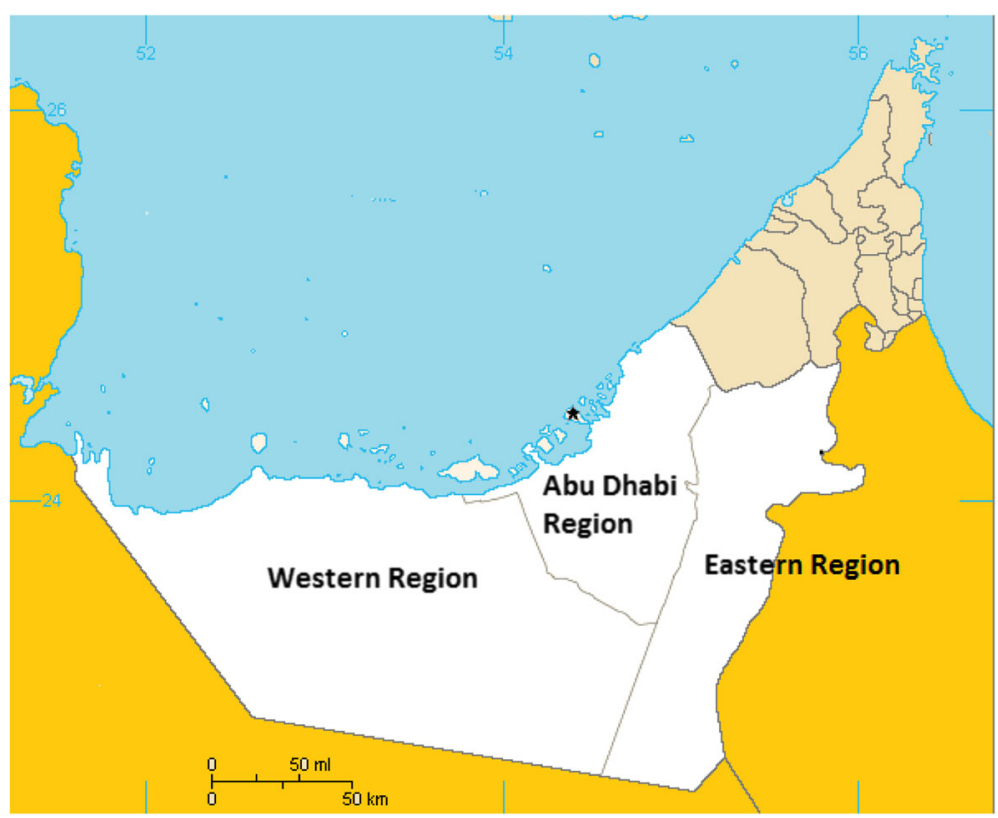

Fig. 1 Map of the Emirate of Abu Dhabi showing the three regions. ${ }^{*}=$ Abu Dhabi City

one study, from Egypt, reported on human brucellosis with an estimated annual incidence of 64-70/100 000 population between 2002 and 2003. Risk factors human brucellosis were consumption of unpasteurized dairy and occupational exposure. The authors concluded that although reliable data is limited, animal, and therefore, human brucellosis remains an important public health problem in all countries of the Middle East [6].

Abu Dhabi is the largest of the seven Emirates that make up the UAE having a population of 2.6 million and a land area of $67,000 \mathrm{~km}^{2}$. Abu Dhabi has three regions namely the Eastern Region, the Western Region and Abu Dhabi Region (Fig. 1). Within Abu Dhabi, many families continue the pastoral way of life of their forebears by maintaining small livestock holdings (Arabic izba) in the rural areas surrounding the towns and cities (Fig. 2). These farms are often makeshift with mixed flocks of goats, sheep and, camels and provide a leisure interest and a family supply of meat and dairy products. Camels are also an important part of local tradition, camel racing is popular and is often accompanied by active camel trading [7]. Considering the popularity of raising sheep, goats and, camels and consuming their milk and dairy products, often without pasteurization, the low reported incidence of human brucellosis is therefore questionable.

A World Health Organization (WHO) commissioned review of the scientific literature on the occurrence of human brucellosis commented on the lack of reliable

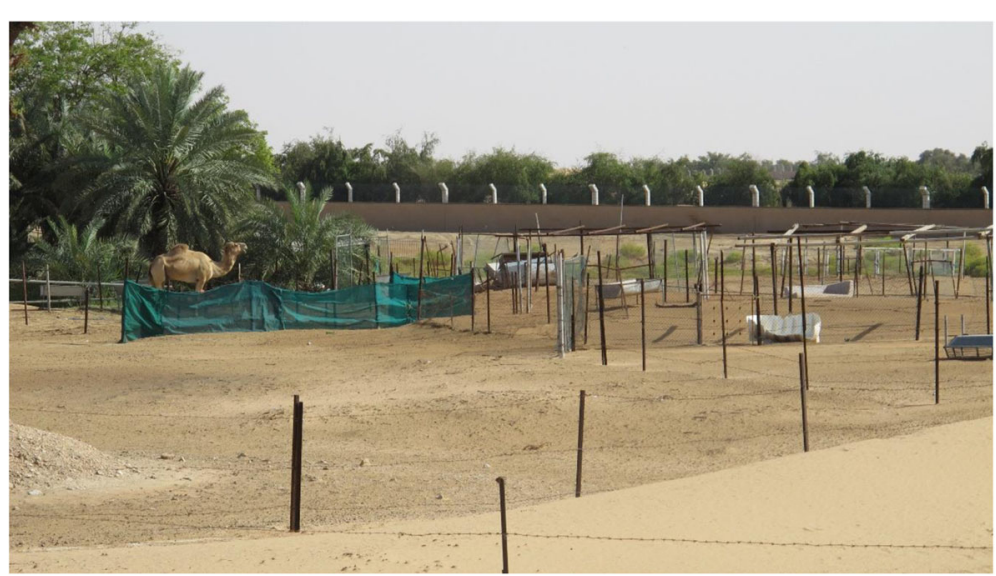

Fig. 2 A typical livestock holding (izba) near Al Ain in the Eastern Region of Abu Dhabi 
incidence data because passively acquired national surveillance data are likely to underestimate the true disease burden [8]. The authors recommended higher quality research and surveillance and an integration of human and animal surveillance data to ensure that the epidemiology of human brucellosis is properly defined and control programs are targeted at high burden areas and emerging foci of infection. A more recent WHO report also once again highlighted the burden of foodborne brucellosis in the Middle Eastern and African regions [9].

In 2009, a new web-based electronic system (e-notification system) replaced the former paper based infectious disease notification system in Abu Dhabi. This has improved the quality of infectious disease surveillance data in Abu Dhabi and for the first time allows the reporting of reliable data on the occurrence of human brucellosis [10]. This is the purpose of this paper in which we update estimates of the incidence of human brucellosis in Abu Dhabi for the 6 years 2010 to 2015 .

\section{Methods}

A dataset comprising date of report, age, gender, nationality, region of residence and status (Table 1) was extracted for each case of human brucellosis reported to the Health Authority Abu Dhabi (HAAD) e-notification system for the 6 year period January 2010 to December 2015.

In the UAE, in official sources, health and other administrative data are typically presented according to two categories of nationality namely those who are Emirati citizens and those who are non-citizens. Citizens are also described as "nationals" and non-citizens as expatriates. This is the terminology used by HAAD and is the one that is used in this paper. The case definition that is used by the e-notification system is the same as the one that is used for surveillance by the Centers for Disease Control and Prevention [11]. As a minimum requirement, physicians will report a clinically compatible illness that is epidemiologically linked to confirmed human or animal brucellosis as a probable case. If there is definitive laboratory evidence of Brucella infection the case is reported as confirmed. All the data used in this study are anonymized so that the identity of any individual case could not be uncovered. Since the data derives from public health surveillance of a notifiable infectious disease

Table 1 Dataset for human brucellosis notifications

\begin{tabular}{ll}
\hline Variable name & Variable value \\
\hline Date of report & Date \\
Age & Years \\
Gender & Male, female \\
Nationality & National, expatriate \\
Region & Eastern, Abu Dhabi, Western \\
Status & Probable, confirmed \\
\hline
\end{tabular}

Table 2 Characteristics of notified cases of human brucellosis, Abu Dhabi 2010-2015

\begin{tabular}{|c|c|c|}
\hline Characteristic & Number & Percent \\
\hline \multicolumn{3}{|l|}{ Gender } \\
\hline Female & 101 & $21 \cdot 0$ \\
\hline Male & 379 & $79 \cdot 0$ \\
\hline Age - years (Mean [SD]) & $30 \cdot 5$ & $16 \cdot 5$ \\
\hline \multicolumn{3}{|l|}{ Age - Categories } \\
\hline $0-19$ years & 111 & $23 \cdot 1$ \\
\hline 20-39 years & 232 & $48 \cdot 3$ \\
\hline 40-59 years & 116 & $24 \cdot 2$ \\
\hline $60+$ years & 21 & $4 \cdot 4$ \\
\hline \multicolumn{3}{|l|}{ Nationality } \\
\hline National & 187 & $39 \cdot 0$ \\
\hline Expatriate & 293 & $61 \cdot 0$ \\
\hline \multicolumn{3}{|l|}{ Region } \\
\hline Abu Dhabi & 247 & $51 \cdot 5$ \\
\hline Eastern & 204 & $42 \cdot 5$ \\
\hline Western & 29 & $6 \cdot 0$ \\
\hline \multicolumn{3}{|l|}{ Diagnosis } \\
\hline Confirmed cases & 328 & $68 \cdot 3$ \\
\hline Probable cases & 152 & $31 \cdot 7$ \\
\hline
\end{tabular}

Source: HAAD e-notification system

it is judged to be exempt from institutional review board assessment.

\section{Statistical analysis}

Descriptive statistics were used to show the number and proportions of the notified cases by year, status (probable, confirmed), age-group, gender, nationality, region and, month of report. Mid-year population estimates are available for Abu Dhabi by age group, gender, nationality and, geographical region for 2010, 2011, 2012, 2013 and,

Table 3 Notifications of human brucellosis, Abu Dhabi 2010-2015 by year and status

\begin{tabular}{|c|c|c|c|c|c|}
\hline \multirow[b]{3}{*}{ Year } & \multicolumn{5}{|c|}{ Brucellosis Cases } \\
\hline & \multirow[t]{2}{*}{$\mathrm{N}$} & \multicolumn{2}{|c|}{ Confirmed } & \multicolumn{2}{|c|}{ Probable } \\
\hline & & $n$ & $\%$ & $n$ & $\%$ \\
\hline 2010 & 47 & 37 & $78 \cdot 7$ & 10 & $21 \cdot 3$ \\
\hline 2011 & 75 & 61 & $81 \cdot 3$ & 14 & $18 \cdot 7$ \\
\hline 2012 & 135 & 96 & $71 \cdot 1$ & 39 & $28 \cdot 9$ \\
\hline 2013 & 99 & 69 & $69 \cdot 7$ & 30 & $30 \cdot 3$ \\
\hline 2014 & 49 & 26 & $53 \cdot 1$ & 23 & $46 \cdot 9$ \\
\hline 2015 & 75 & 39 & $52 \cdot 0$ & 36 & $48 \cdot 0$ \\
\hline Total & 480 & 328 & $68 \cdot 3$ & 152 & 31.7 \\
\hline
\end{tabular}

Source: HAAD e-notification system

Confidence Intervals are calculated using the Poisson distribution Abbreviations: $N R$ notification rate, $\mathrm{Cl}$ confidence interval 


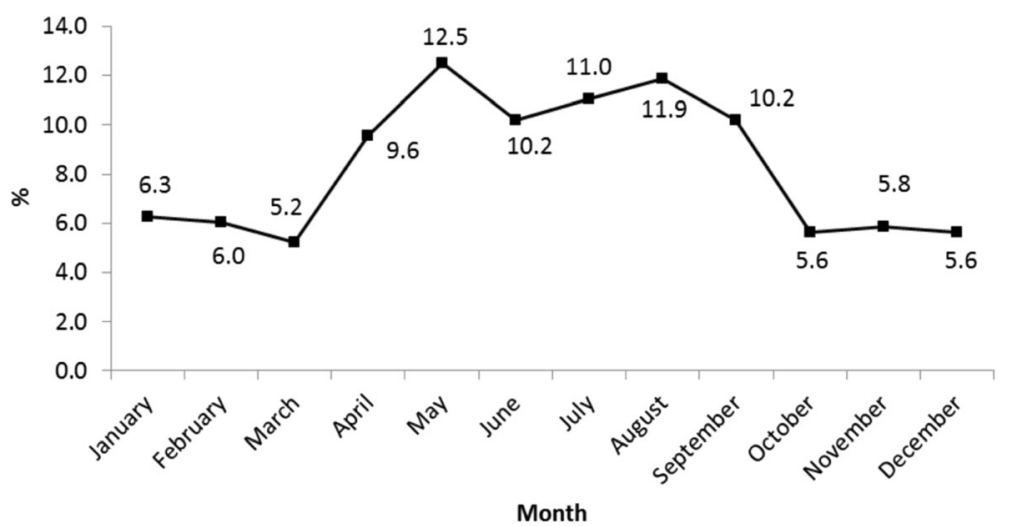

Fig. 3 Notifications of human brucellosis (\%), Abu Dhabi 2010-2015 by month of report. Source: HAAD e-notification system

2014 [12]. Estimates are not available for 2015 but for the purpose of this analysis have been extrapolated based on age and nationality population growth rates. Average annual brucellosis rates by age-group, gender, nationality and, geographical region have been calculated using the total number of reports as the numerator and the mid-year population as the denominator, both summed over the 6 years 2010-2015. The age-groups that are used (0-19, 20-39, 40-59 and, 60+) were chosen pragmatically to represent children and adolescents, those of young working age, middle age and, elderly. Confidence intervals for the rates were computed using a Poisson distribution. Incidence rate ratios were used to compare rates by age-group, gender, nationality and, region. For this analysis, to overcome the issue of dispersion of data, negative binomial regression was used rather than Poisson regression. Negative binomial regression models the probability that a person with a particular characteristic experiences an event (in this case infection with Brucella). Microsoft Excel 2010@ was used for data entry and analyses were conducted using Stata (version 14). For statistical significance, $95 \%$ CIs and $p$ value $<0.05$ were used.

\section{Results}

In the six-year period 2010-2015, a total of 480 cases of brucellosis were reported to the HAAD e-notification system. There were more males (79 \%) than females, the mean age was $30,48 \%$ were in the $20-39$ year age group and $39 \%$ were nationals. Fifty one percent were from Abu Dhabi Region, $42 \%$ were from the Eastern Region and only $6 \%$ were from the Western Region. Two hundred and ninety cases $(72 \%)$ were confirmed by laboratory testing (Table 2). Forty seven cases were reported in 2010, 75 cases were reported in 2011, 135 cases were reported in 2012, there were 99 reports in 2013, 49 reports in 2014 and, 75 reports in 2015 (Table 3). The annual number of cases peaked in 2012 but in both 2012 and 2013 a smaller proportion of cases were confirmed compared to the two earlier years. In 2014 and 2015 the proportion of confirmed cases has plateaued at about $50 \%$. To improve statistical precision, the six years data has been aggregated for the following analyses. Figure 3 confirms the seasonal pattern of brucellosis

Table 4 Crude notification rates (per 100,000 population) and

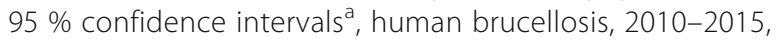
Abu Dhabi Emirate, United Arab Emirates

\begin{tabular}{llll}
\hline & $\mathrm{N}(\%)$ & $\mathrm{NR}$ & $95 \% \mathrm{Cl}^{\mathrm{a}}$ \\
\hline Overall & 480 & $3 \cdot 31$ & $3 \cdot 02-3 \cdot 62$ \\
Gender & & & \\
Male & $379(79 \cdot 0)$ & $3 \cdot 8$ & $3 \cdot 43-4 \cdot 21$ \\
$\quad$ Female & $101(21 \cdot 0)$ & $2 \cdot 23$ & $1 \cdot 82-2 \cdot 71$ \\
Nationality & & & \\
Nationals & $187(39 \cdot 0)$ & $6 \cdot 39$ & $5 \cdot 50-7 \cdot 37$ \\
Expatriates & $293(61 \cdot 0)$ & $2 \cdot 53$ & $2 \cdot 25-2 \cdot 84$ \\
Age & & & \\
0-19 years & $111(23 \cdot 1)$ & $3 \cdot 41$ & $2 \cdot 81-4 \cdot 11$ \\
$20-39$ years & $232(48 \cdot 3)$ & $2 \cdot 84$ & $2 \cdot 49-3 \cdot 23$ \\
$40-59$ years & $116(24 \cdot 2)$ & $4 \cdot 13$ & $3 \cdot 41-4 \cdot 95$ \\
$60+$ years & $21(4 \cdot 4)$ & $8 \cdot 03$ & $4 \cdot 97-12 \cdot 27$ \\
Year & & & \\
2010 & $47(9 \cdot 8)$ & $2 \cdot 36$ & $1 \cdot 74-3 \cdot 14$ \\
2011 & $75(15 \cdot 6)$ & $3 \cdot 47$ & $2 \cdot 73-4 \cdot 35$ \\
2012 & $135(28 \cdot 1)$ & $5 \cdot 78$ & $4 \cdot 85-6 \cdot 84$ \\
2013 & $99(20 \cdot 6)$ & $4 \cdot 04$ & $3 \cdot 28-4 \cdot 91$ \\
2014 & $49(10 \cdot 2)$ & $1 \cdot 83$ & $1 \cdot 36-2 \cdot 42$ \\
2015 & $75(15 \cdot 6)$ & $2 \cdot 61$ & $2 \cdot 05-3 \cdot 27$ \\
Region & & & \\
Abu Dhabi & $247(51 \cdot 5)$ & $2 \cdot 79$ & $2 \cdot 45-3 \cdot 16$ \\
Eastern & $204(42 \cdot 5)$ & $5 \cdot 22$ & $4 \cdot 53-5 \cdot 99$ \\
Western & & $1 \cdot 69$ & $1 \cdot 13-2 \cdot 42$ \\
\hline
\end{tabular}

Source: HAAD e-notification system and Statistics Center Abu Dhabi 
with reports peaking in the summer months associated with warmer weather and farming practices. The overall crude notification rate was $3 \cdot 3$ per 100,000 population. Based on $95 \%$ confidence intervals, significantly higher rates were observed in males $(3 \cdot 8)$ than females $(2 \cdot 2)$, nationals $(6 \cdot 4)$ compared with expatriates $(2 \cdot 5)$, those aged 60 years and over (8.0) and Eastern Region residents $(5 \cdot 2)$. No obvious time trend was discernible (Table 4).

Table 5 summarises the reports by age-group, gender, nationality and geographical region of residence. Most cases were reported from the Eastern Region amongst expatriate males of working age and from Abu Dhabi Region amongst national males and females of younger age and expatriate males of working age. This pattern reflects the relative population density in these areas but additional caution is required when interpreting this geographical distribution since region of report will not necessarily be the same as the region in which infection was acquired. This may be particularly relevant for nationals who may reside in Abu Dhabi but spend leisure time in the Eastern Region (see below). Specific rates are also shown in Table 5. The highest rates are seen amongst expatriate males of working age in the Eastern Region (approximately 10 per 100,000) and amongst UAE nationals of all ages and both genders in Abu Dhabi (4-24 per 100,000). Incidence rate ratios were used to further compare the rates. The adjusted data (Table 6) suggest that being aged 40 years and over, of male gender, of Emirati nationality and resident in Abu Dhabi Region are independently associated with an increased risk of brucellosis.

\section{Discussion}

In this study, we have estimated the overall crude human brucellosis notification rate for Abu Dhabi for $2010-2015$ as $3 \cdot 3$ per 100,000 population per year. Our estimate updates the previously published estimate for the United Arab Emirates of $4 \cdot 1$ per 100,000 which was based on Ministry of Health data for the years 1994-2000. This new Abu Dhabi estimate is in contrast to higher rates seen in other Middle East and North African countries

Table 5 Human brucellosis notification rates (per 100,000 population) and 95 \% confidence intervals ${ }^{a}$, 2010-2015, Abu Dhabi Emirate, United Arab Emirates, by gender, age-group, nationality and, region

\begin{tabular}{|c|c|c|c|c|c|c|c|c|c|c|c|c|}
\hline & \multicolumn{6}{|c|}{ UAE Nationals } & \multicolumn{6}{|c|}{ Expatriates } \\
\hline & \multicolumn{3}{|c|}{ Male } & \multicolumn{3}{|c|}{ Female } & \multicolumn{3}{|l|}{ Male } & \multicolumn{3}{|c|}{ Female } \\
\hline & $\mathrm{n}$ & NR & $95 \% \mathrm{Cl}$ & $n$ & NR & $95 \% \mathrm{Cl}$ & $n$ & NR & $95 \% \mathrm{Cl}$ & $n$ & NR & $95 \% \mathrm{Cl}$ \\
\hline All Regions, all ages & 122 & $8 \cdot 21$ & $6 \cdot 82-9 \cdot 80$ & 65 & $4 \cdot 51$ & $3 \cdot 48-5 \cdot 75$ & 257 & $3 \cdot 03$ & $2 \cdot 67-3 \cdot 43$ & 36 & $1 \cdot 17$ & $0 \cdot 09-1 \cdot 62$ \\
\hline \multicolumn{13}{|l|}{ All Regions } \\
\hline $0-19$ years & 58 & $7 \cdot 87$ & $5 \cdot 97-10 \cdot 17$ & 27 & $3 \cdot 89$ & $2 \cdot 56-5 \cdot 65$ & 18 & $1 \cdot 89$ & $1 \cdot 12-2 \cdot 99$ & 8 & 0.92 & $0 \cdot 40-1 \cdot 81$ \\
\hline 20-39 years & 33 & $6 \cdot 34$ & $4 \cdot 37-8 \cdot 91$ & 16 & $3 \cdot 01$ & $1 \cdot 72-4 \cdot 89$ & 167 & $3 \cdot 03$ & $2 \cdot 59-3 \cdot 52$ & 16 & $1 \cdot 00$ & $0 \cdot 57-1 \cdot 62$ \\
\hline $40-59$ years & 22 & $12 \cdot 72$ & $7 \cdot 97-19 \cdot 26$ & 17 & $9 \cdot 94$ & $5 \cdot 79-15 \cdot 92$ & 67 & $3 \cdot 52$ & $2 \cdot 73-4 \cdot 47$ & 10 & $1 \cdot 79$ & $0 \cdot 86-3 \cdot 28$ \\
\hline $60+$ years & 9 & $16 \cdot 15$ & $7 \cdot 38-30 \cdot 65$ & 5 & $11 \cdot 19$ & $3 \cdot 63-26 \cdot 11$ & 5 & $4 \cdot 65$ & $1 \cdot 51-10 \cdot 85$ & 2 & $3 \cdot 73$ & $0 \cdot 45-13 \cdot 48$ \\
\hline \multicolumn{13}{|l|}{ Abu Dhabi Region } \\
\hline $0-19$ years & 47 & $12 \cdot 34$ & $9 \cdot 06-16 \cdot 4$ & 22 & $6 \cdot 18$ & $3 \cdot 87-9 \cdot 36$ & 14 & $2 \cdot 29$ & $1 \cdot 25-3 \cdot 84$ & 4 & 0.69 & $0 \cdot 06-1 \cdot 79$ \\
\hline 20-39 years & 26 & $9 \cdot 58$ & $6 \cdot 26-14 \cdot 04$ & 13 & $4 \cdot 24$ & $2 \cdot 26-7 \cdot 25$ & 46 & $1 \cdot 34$ & $0 \cdot 98-1 \cdot 79$ & 10 & 0.92 & $0 \cdot 44-1 \cdot 69$ \\
\hline $40-59$ years & 14 & $14 \cdot 58$ & $7 \cdot 97-24 \cdot 46$ & 13 & $13 \cdot 85$ & $7 \cdot 38-23 \cdot 69$ & 15 & $1 \cdot 34$ & $0 \cdot 75-2 \cdot 1$ & 9 & $2 \cdot 39$ & $1 \cdot 09-4 \cdot 54$ \\
\hline $60+$ years & 7 & $24 \cdot 12$ & $9 \cdot 70-49 \cdot 69$ & 4 & $17 \cdot 13$ & $4 \cdot 67-43 \cdot 86$ & 2 & $2 \cdot 84$ & $0 \cdot 34-10 \cdot 26$ & 1 & $2 \cdot 49$ & $0 \cdot 63-13 \cdot 88$ \\
\hline \multicolumn{13}{|l|}{ Eastern Region } \\
\hline $0-19$ years & 9 & $2 \cdot 83$ & $1 \cdot 30-5 \cdot 38$ & 5 & $1 \cdot 65$ & $0 \cdot 53-3 \cdot 84$ & 4 & $1 \cdot 49$ & $0 \cdot 41-3 \cdot 82$ & 1 & $0 \cdot 41$ & $0 \cdot 01-2 \cdot 30$ \\
\hline 20-39 years & 7 & $3 \cdot 47$ & $1 \cdot 39-7 \cdot 15$ & 3 & $1 \cdot 50$ & $0 \cdot 31-4 \cdot 39$ & 106 & $9 \cdot 14$ & $7 \cdot 49-11 \cdot 06$ & 5 & $1 \cdot 14$ & $0 \cdot 37-2 \cdot 66$ \\
\hline 40-59 years & 8 & $12 \cdot 39$ & $5 \cdot 35-24 \cdot 41$ & 4 & $5 \cdot 78$ & $1 \cdot 57-14 \cdot 79$ & 47 & $10 \cdot 72$ & $7 \cdot 88-14 \cdot 25$ & 1 & $0 \cdot 82$ & $0 \cdot 02-4 \cdot 58$ \\
\hline $60+$ years & 1 & $4 \cdot 24$ & $0 \cdot 11-23 \cdot 64$ & 1 & $5 \cdot 33$ & $0 \cdot 13-29 \cdot 68$ & 2 & $7 \cdot 95$ & $0 \cdot 96-28 \cdot 72$ & 0 & 0 & - \\
\hline \multicolumn{13}{|l|}{ Western Region } \\
\hline 0-19 years & 2 & $5 \cdot 16$ & $0 \cdot 63-18 \cdot 63$ & 0 & 0 & - & 0 & 0 & $0 \cdot 00-5 \cdot 11$ & 3 & $5 \cdot 63$ & $1 \cdot 16-16 \cdot 44$ \\
\hline 20-39 years & 0 & 0 & - & 0 & 0 & - & 15 & $1 \cdot 62$ & $0 \cdot 91-2 \cdot 67$ & 1 & $1 \cdot 37$ & $0 \cdot 035-7 \cdot 62$ \\
\hline 40-59 years & 0 & 0 & - & 0 & 0 & - & 5 & $1 \cdot 45$ & $0 \cdot 47-3 \cdot 39$ & 0 & 0 & - \\
\hline $60+$ years & 1 & $31 \cdot 77$ & $0 \cdot 80-176 \cdot 99$ & 0 & 0 & - & 1 & $8 \cdot 34$ & $0 \cdot 21-46 \cdot 45$ & 1 & $66 \cdot 89$ & $1 \cdot 69-372 \cdot 69$ \\
\hline
\end{tabular}

Source: HAAD e-notification system and Statistics Center Abu Dhabi Abbreviations: $N R$ notification rate, $\mathrm{Cl}$ confidence interval

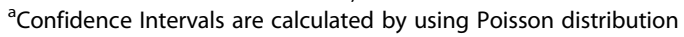


Table 6 Unadjusted and adjusted human brucellosis incidence rate ratios and 95 \% confidence intervals ${ }^{a}$, 2010-2015, Abu Dhabi Emirate, United Arab by age-group, gender, nationality and, Region

\begin{tabular}{|c|c|c|c|c|c|c|}
\hline \multirow{3}{*}{ Predictors } & \multicolumn{3}{|c|}{ Unadjusted negative binomial regression } & \multicolumn{3}{|c|}{ Adjusted negative binomial regression } \\
\hline & \multicolumn{3}{|c|}{ Brucellosis } & \multicolumn{3}{|c|}{ Brucellosis } \\
\hline & IRR & $95 \% \mathrm{Cl}$ & $P$ Value & IRR & $95 \% \mathrm{Cl}$ & $P$ Value \\
\hline \multicolumn{7}{|l|}{ Age } \\
\hline $0-19$ years & Ref & & & Ref & & \\
\hline 20-39 years & 0.95 & $0 \cdot 44-2 \cdot 05$ & $0 \cdot 905$ & $1 \cdot 17$ & $0 \cdot 63-2 \cdot 17$ & 0.625 \\
\hline $40-59$ years & $1 \cdot 74$ & $0 \cdot 79-3 \cdot 81$ & $0 \cdot 168$ & $1 \cdot 95$ & $1 \cdot 04-3 \cdot 64$ & $0 \cdot 037$ \\
\hline $60+$ years & $2 \cdot 90$ & $1 \cdot 17-7 \cdot 15$ & $0 \cdot 021$ & $2 \cdot 81$ & $1 \cdot 31-6 \cdot 04$ & $0 \cdot 008$ \\
\hline \multicolumn{7}{|l|}{ Gender } \\
\hline Female & Ref & & & Ref & & \\
\hline Male & $1 \cdot 84$ & $0 \cdot 98-3 \cdot 43$ & $0 \cdot 057$ & $2 \cdot 13$ & $1 \cdot 32-3 \cdot 45$ & $0 \cdot 002$ \\
\hline \multicolumn{7}{|l|}{ Nationality } \\
\hline Expatriate & Ref & & & Ref & & \\
\hline Emirati National & $2 \cdot 54$ & $1 \cdot 45-4 \cdot 45$ & $0 \cdot 001$ & $2 \cdot 52$ & $1 \cdot 55-4 \cdot 11$ & $<0.001$ \\
\hline \multicolumn{7}{|l|}{ Region } \\
\hline Western & Ref & & & Ref & & \\
\hline Abu Dhabi & $3 \cdot 04$ & $1 \cdot 25-7 \cdot 38$ & 0.014 & $2 \cdot 09$ & $1 \cdot 01-4 \cdot 35$ & $0 \cdot 048$ \\
\hline Eastern & $1 \cdot 99$ & $0 \cdot 81-4 \cdot 91$ & $0 \cdot 133$ & $1 \cdot 78$ & $0 \cdot 87-3 \cdot 67$ & $0 \cdot 116$ \\
\hline
\end{tabular}

Source: HAAD e-notification system and Statistics Center Abu Dhabi Abbreviations: IRR incidence rate ratio, $\mathrm{Cl}$ confidence interval

${ }^{a}$ Confidence Intervals are calculated using negative binomial regression

(Syria 160, Saudi Arabia 21, Iraq 28 and Algeria 8). Also, in the UAE in 2009, 158 brucellosis cases were reported in a population which at that time was estimated to be about 8 million. This gives a crude incidence rate of approximately 2 per 100,000 population per year which is not dissimilar to the new estimate reported here [13, 14]. However a new finding, from this study, is the higher incidence of brucellosis in certain population subgroups notably expatriate males of working age in the Eastern Region (approximately 10 per 100,000) and UAE nationals of all ages and both genders in Abu Dhabi (4-24 per $100,000)$. Incidence rate ratios provide further evidence for the risk factors of human brucellosis in Abu Dhabi. Aged 40 years and over, of male gender, of Emirati nationality and, resident in Abu Dhabi Region identifies a section of UAE society who are at an increased risk of brucellosis.

Our findings reflect environmental and behavioral factors linked to occupation and leisure time activities. In countries where food hygiene practices prevent foodborne brucellosis, the disease is largely occupational, and the majority of cases are seen in males between the ages of 20 and 45 years. However, in countries where untreated dairy products are consumed the wider population is at risk and cases can occur in women and children. Both of these factors explain the distribution of cases reported here. Livestock keeping, particularly of small ruminants such as sheep and goats in which Brucella infection is prevalent, is popular amongst Emirati families who seek to preserve their pastoral heritage. Indeed in Abu Dhabi, in 2014, there were 24,000 livestock holdings accommodating 3.4 million sheep, goats and, camels [15]. Of these over half $(15,000)$ are in the Eastern Region which traditionally has been the UAE center of agricultural activity. Many of these farms are small and makeshift with mixed herds and low standards of hygiene. There is little official data on animal brucellosis in UAE [16] but a serological survey carried out in 2009, in the three regions of $\mathrm{Abu}$ Dhabi, found that the prevalence of Brucella antibodies varied from 5.3 to $10.7 \%$ in sheep and goats and 4.8-8.8 \% in camels [17]. Opportunities for human transmission occur when herdsmen (invariably expatriate men of working age) handle and feed animals and assist with parturition and when owners (Emiratis) and their families have contact with animals during visits or consume unpasteurized milk and other food products. Our data also shows a seasonal variation in the incidence of human brucellosis with most cases occurring in the spring and summer. This period coincides with animal breeding cycles and contrasts with tropical and subtropical areas, where animal breeding can extend throughout the year and a seasonal pattern of human disease is not seen.

Our findings must be interpreted in light of the acknowledged limitations of this study. Cases of brucellosis are reported passively by clinicians and therefore, as with all such surveillance systems, are subject to underreporting. Also not all cases are confirmed by appropriate 
laboratory tests so that misclassification can occur. That said, the web-based e-notification system maximizes engagement of clinicians and gives the best possible prospect of thorough ascertainment of the numerators while accurate population estimates are available for use as the denominators. The e-notification system attempts to collect a detailed dataset for each case of brucellosis but this is not always completed by the notifying clinician and this missing data means that we have not been able to report other correlates of infection such as occupation, specific risk behaviors, travel, clinical features and outcomes. Certainly, improving the completeness of our dataset would add to the understanding of the risk factors for human brucellosis in Abu Dhabi. However passive surveillance systems are prone to interviewer bias and alternative research design may be more appropriate [18].

Control of human brucellosis depends on the control of animal brucellosis by a combination of vaccination and testing and slaughter of infected animals along with better farm biosecurity and hygiene [19]. Cattle brucellosis has been eliminated in some countries but the control of brucellosis in small ruminants such as sheep and goats is more challenging. In Abu Dhabi it is not clear how this can be achieved given the very large number of small noncommercial farms and the enduring popularity amongst Emiratis of continuing the traditional pastoral way of life, spending time on their farms, looking after their animals and consuming untreated milk and dairy products. Indeed, over the six years covered by this study there is no sign of a downwards trend in human brucellosis rates.

\section{Conclusion}

In some sub-groups of the Abu Dhabi population, brucellosis is a significant infection with rates in excess of 10 per 100,000 population per year. These are lower than the historical rates reported from some neighboring countries but are higher than might be expected based on past local surveillance data. These updated estimates have been made possible by better quality data from a new e-notification system. The data shows that some sub-sections of the population are at increased risk of brucellosis because of increased exposure due to occupation or leisure related activities. The popularity of small non-commercial livestock farms with Emirati families is unique and will challenge any efforts to introduce control measures to eliminate Brucella infection from livestock in Abu Dhabi.

\section{Abbreviations \\ HAAD: Health Authority Abu Dhabi; UAE: United Arab Emirates; WHO: World} Health Organization

\section{Funding}

The study did not require specific funding. The authors alone are responsible for the views expressed in this article and they do not necessarily represent the views of other organizations.

\section{Availability of data and materials}

We would not be able to share the dataset without the permission of Health Authority Abu Dhabi. However aggregate data is available at http:// www.haad.ae/HAAD/LinkClick.aspx?fileticket=kCGuarfuxNk\%3d\&tabid=1177

\section{Authors' contributions}

NAS: literature search, study design, data interpretation, writing. FA: figures, data analysis, data interpretation. FAH: data collection, data interpretation, writing. BA: data collection, data interpretation, writing. IB: literature search, figures, data analysis, data interpretation, writing. All authors read and approved the final manuscript.

\section{Competing interests}

All authors have completed the ICMJE Form for Disclosure of Potential Conflicts of Interest. The authors declare that they have no competing interests.

\section{Consent for publication}

Not applicable.

Ethics approval and consent to participate

Not applicable.

\section{Author details}

${ }^{1}$ Communicable Disease Control and Prevention Centre, Khasab Hospital, Khasab, Oman. ${ }^{2}$ Institute of Public Health, College of Medicine and Health Sciences, United Arab Emirates University, PO Box 17666, Al Ain, United Arab Emirates.

Received: 16 April 2016 Accepted: 5 October 2016

Published online: 12 October 2016

\section{References}

1. Corbel MJ. Brucellosis in humans and animals [Internet]. Geneva: World Health Organization; 2006 press; 2006 [cited 2016 Mar 02]. Available from: http://www.who.int/csr/resources/publications/Brucellosis.pdf

2. Seleem MN, Boyle SM, Sriranganathan N. Brucellosis: a re-emerging zoonosis. Vet Microbiol. 2010;140:392-8.

3. Pappas G, Papadimitriou P, Akritidis N, Christou L, Tsianos EV. The new global map of human brucellosis. Lancet Infect Dis. 2006;6:91-9.

4. FAOSTST [Internet]. Rome, Italy: Food and Agriculture Organization of The United Nations; 2016 [cited 2016 Mar 1]. Available from: http://faostat3.fao. org/home/E

5. Werner U. Zoonoses in the Arabian Peninsula. Saudi Med J. 2014;35(12):1455-62.

6. Musallam II, Abo-Shehada MN, Hegazy YM, Holt HR, Guitian FJ. Systematic review of brucellosis in the Middle East: disease frequency in ruminants and humans and risk factors for human infection. Epidemiol Infect. 2016;144:671-85.

7. Sprague LD, Al-Dahouk S, Neubauer H. A review on camel brucellosis: a zoonosis sustained by ignorance and indifference. Pathogens Global Health. 2012;106(3):144-9.

8. Dean AS, Crump L, Greter H, Schelling E, Zinsstag J. Global burden of human brucellosis: a systematic review of disease frequency. PLoS Negl Trop Dis. 2012;6(10):e1865. doi:10.1371/journal.pntd.0001865.

9. World Health Organization. WHO estimates of the global burden of foodborne diseases: foodborne disease burden epidemiology reference group 2007-2015. Geneva: World Health Organization; 2015.

10. Health Authority Abu Dhabi. Communicable Diseases Bulletin Volume 1: Fourth Quarter 2010 (October- December) [Internet]. Abu Dhabi: Health Authority Abu Dhabi; 2011 [cited 2106 March 01] Available from: http://www. haad.ae/HAAD/LinkClick.aspx?fileticket=WCJxOIMroL4\%3d\&tabid=1159

11. National Notifiable Diseases Surveillance System (NNDSS) [Internet]. Atlanta, USA: Centers for Disease Control and Prevention; 2010 [updated 2015 May 06; cited 2016 Mar 1]. Available from: http://wwwn.cdc.gov/nndss/ conditions/brucellosis/case-definition/2010/Clinical Description

12. Statistics Center Abu Dhabi. Statistical Yearbook of Abu Dhabi 2015. 3. Population and Demography [Internet]. Abu Dhabi: Statistics Center Abu Dhabi; 2015 [cited 2016 Feb 27] Available from: https://www.scad.ae/en/ Pages/ThemeReleaseDetail.aspx?ReleaselD $=675 \&$ ThemelD $=4$

13. Health Policies Sector, Ministry of Health, UAE. 2010 annual report. Dubai: United Arab Emirates Ministry of Health; 2010. 
14. Federal Competiveness and Statistics Authority [Internet]. Abu Dhabi: Federal Competiveness and Statistics Authority; 2015 [updated 2015 Dec 10; cited 2016 Mar 02]. Available from: http://atlas.fcsa.gov.ae/Forms/Atlas/ estimate/images/87.jpg

15. Statistics Center Abu Dhabi. Livestock Statistics 2014 [Internet]. Abu Dhabi: Statistics Center Abu Dhabi; 2015 [cited 2016 March 01] Available from: https://www.scad.ae/en/Pages/ThemePublication.aspx?PID=98\&ThemelD=7

16. World Animal Health Information Database (WAHIS) Interface [Internet]. Paris, France: World Organization for Animal Health (OIE); 2016 [cited 2016 Mar 1]. Available from: http://www.oie.int/wahis_2/public/wahid.php/ Wahidhome/Home

17. Mohammed MA, Shigidy MT, Al Juboori AY. Sero-prevalence and epidemiology of brucellosis in camels, sheep and goats in Abu Dhabi Emirate. Int J Anim Vet Adv. 2013;5(2):82-6.

18. Gibbons $\mathrm{CL}$, et al. Measuring underreporting and under-ascertainment in infectious disease datasets: a comparison of methods. BMC Public Health. 2014;14:147.

19. Food and Agriculture Organization. Brucella melitensis in Eurasia and the Middle East. FAO Animal Production and Health Proceedings 2010. No. 10. Rome.

\section{Submit your next manuscript to BioMed Central} and we will help you at every step:

- We accept pre-submission inquiries

- Our selector tool helps you to find the most relevant journal

- We provide round the clock customer support

- Convenient online submission

- Thorough peer review

- Inclusion in PubMed and all major indexing services

- Maximum visibility for your research

Submit your manuscript at www.biomedcentral.com/submit 